\title{
A Biblioteca do Museu Paraense Emílio Goeldi
}

\author{
Léa Diniz $\left({ }^{*}\right)$
}

\section{Resumo}

\begin{abstract}
A Biblioteca foi criada em 1894 para servir de apoio bibliográfico às pesquisas realizadas no Museu e acompanhou, conseqüentemente, as fases de crescimento e declínio desta instituição. A partir de 1954, por força de um convênio firmado com o Governo do Estado do Pará pelo qual o Museu passou a ser administrado pelo CNPq através do INPA, a Biblioteca recebeu nova organização, maiores recursos humanos e financeiros, tomando novo impulso e reconquistando sua posição entre as melhores do país. Neste ano em que se comemora o $300^{\circ}$ aniversário do CNPq, a Biblioteca está com um acervo especializado bastante significativo (109.364 documentos), participa de programas de cooperação nacionais e internacionais, realiza intercâmbio com 3.245 instituições do Brasil e do Exterior e, além de sua finalidade restrita de apoio às pesquisas realizadas pelo Museu, faz um atendimento médio de 8.300 consultas anuais.
\end{abstract}

\section{INTRODUÇÃO}

A criação de uma biblioteca no Museu Goeldi resultou de iniciativa do próprio Dr. Emílio Goeldi quando, a convite do governo do Estado do Pará, em 1894, iniciou a organização do então Museu Paraense e sentiu a necessidade de apoio bibliográfico básico para o trabalho dos cientistas por ele convidados para realizar pesquisas na Amazônia. O pequeno acervo que conseguiu reunir para a criação da biblioteca teve rápida expansão, devido ao sistema de intercâmbio de publicações com instituições nacionais e internacionais, iniciado com a edição dos primeiros Boletins.

A crise econômica que se instaurou em toda a região a partir da queda da borracha refletiu-se de maneira marcante no Museu e na Biblioteca, deixando como conseqüências da redução dos recursos, a diminuição sensivel das pesquisas com a evasão dos cientistas para outras regiões mais favorecidas, e a falta de publicações que levou à interrupção do intercâmbio, até a sua completa desatualização.
Para salvar o Museu de um iminente colapso, o Conselho Nacional de Desenvoivimento Científico e Tecnológico (CNPq) firmou, em 1954, com o Governo do Estado do Pará, um convênio pelo qual assumia administrativa e financeiramente o Museu. Com este novo impulso, a Biblioteca recebeu nova organização, novos recursos, e vem, gradativamente, reconquistando seu lugar entre as mais importantes do país.

\section{SITUAÇÃO EM 1955}

Ao assumir a administração do Museu $\mathrm{Pa}$ raense Emílio Goeldi em 1955, o CNPq convidou para a reorganização da Biblioteca, Clara Maria Galvão, Bibliotecária do Museu Nacional de onde foi requisitada. Ao chegar e assumir esta chefia, Clara Maria Galvão elaborou um relatório dando contas da situação em que se encontravam as instalações e o acervo bibliográfico, e das necessidades para iniciar o trabalho de reorganização.

Em seu primeiro relatório, de outubro de 1955, encontramos as seguintes informações:

(...) O acervo é de 17.917 volumes (...). Está dividido por assunto Botânica, Zoologia (...), Geografia e História, Etnologia, Geologia, Agricultura e Miscelânea $(. .$.$) . A arrumação nas estantes é fixa,$ passando numa mesma seqüência numérica de um assunto para outro.

Catálogos: autor, assunto e matéria ...

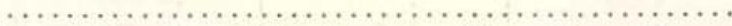
O registro de publicaçōes era feito até então em livros, sem levar em conta o tipo de publicação.

Em outro local do mesmo relatório, no item "B - Plano a curto prazo", encontra-se.

(...) Até agora foi adquirida uma máquina de escrever tipo "elite" para confecção de fichas. Ainda são necessários: fichários (...), livros de registro $(\ldots)$, carimbos $\operatorname{secos}(\ldots)$, fichas perfura-

(*) Museu Paraense Emílio Goeldi, Belém. 
das $(\ldots)$, fichas para periódicos $(\ldots)$, fichas para empréstimos e para consultas. Esse material, na medida das possibilidades de verba, está sendo adquirido.

(...) A Biblioteca se ressente de literatura atual, sendo urgente a aquisição de material bibliográfico (...). Há ainda a considerar a aquisição de livros esgotados: damos prioridade às publicaçōes editadas por este Museu, como o Boletim, do qual só possuimos uma única coleçăo completa e alguns volumes em estado precário.

No mesmo relatório item " $\mathrm{C}$ - Plano a longo prazo" temos ainda:

A Biblioteca deste Museu é especializada e esse critério deverá ser mantido: Ciências Naturais, Etnologia e assuntos sobre a Amazônia.

Pessoal - a falta de recursos de biblioteconomia e o mercado de trabalho reduzido acarreta a carência de pessoal especializado. Acreditamos que essa dificuldade poderá ser sanada com a organização de um curso prático, intensivo ...

\section{ADMINISTRAÇÃO CNPq}

Em dezembro de 1955 o relatório das atividades realizadas na Biblioteca diz o seguinte:

No fim do exercício de 1955 foram adquiridos dois conjuntos de estantes de aço que serão instalados em 2 salas que estão sendo reformadas para esse fim. Os livros que até então estavam distribuídos em 9 salas, colocados em estantes fechadas de madeira e vidro, com localizaçăo fixa, serão arrumados segundo a técnica moderna (...), publicações periódicas separadas de obras propriamente ditas, o que permite a intercalação das publicaçōes dentro do assunto correspondente. Reunindo os volumes nesses dois blocos será facilitado o controle do acervo e o acesso às estantes para consulta.

As salas restantes serão aproveitadas para salas de trabalho, de leitura e referência de mapas e de depósito de publicações do Museu.

Expedido o v. 11 fasc. 1 do Boletim do Museu para 253 instituições nacionais e estrangeiras...

QUADRO 1 - Acervo bibliográfico: crescimento

\begin{tabular}{|c|c|c|c|c|c|c|}
\hline Ano & Livros & Folhetos & Mat. Especiais & Periódicos & Total & Crescimento \\
\hline 1954 & 4.545 & 5.749 & - & 7.623 & 17.917 & - \\
\hline 1955 & 4.640 & 5.867 & 29 & 8.000 & 18.536 & 619 \\
\hline 1956 & 5.089 & 5.964 & 30 & 9.545 & 20.628 & 2.092 \\
\hline 1957 & 5.362 & 6.055 & 41 & 10.467 & 21.925 & 1.307 \\
\hline 1958 & 5.529 & 6.127 & 86 & 11.700 & 23.442 & 1.517 \\
\hline 1959 & 5.626 & 6.127 & 129 & 13.549 & 25.431 & 1.989 \\
\hline 1960 & 6.038 & 7.860 & 153 & 14.862 & 28.913 & 3.482 \\
\hline 1961 & 6.267 & 8.098 & 210 & 17.188 & 31.763 & 2.850 \\
\hline 1962 & 6.571 & 8.515 & 223 & 19.784 & 35.093 & 3.330 \\
\hline 1963 & 6.948 & 8.676 & 266 & 22.354 & 38.244 & 3.151 \\
\hline 1964 & 7.226 & 9.096 & 310 & 25.331 & 41.963 & 3.719 \\
\hline 1965 & 7.414 & 9.271 & 429 & 28.210 & 45.324 & 3.361 \\
\hline 1966 & 7.812 & 9.559 & 582 & 31.420 & 49.373 & 4.049 \\
\hline 1967 & 8.660 & 9.935 & 612 & 35.445 & 54.652 & 5.279 \\
\hline 1968 & 9.061 & 10.065 & 671 & 38.071 & 57.868 & 3.216 \\
\hline 1969 & 9.678 & 10.309 & 671 & 41.433 & 62.191 & 4.323 \\
\hline 1970 & 10.055 & 10.375 & 671 & 45.856 & 66.957 & 4.766 \\
\hline 1971 & 10.366 & 10.827 & 720 & 50.051 & 71.964 & 5.007 \\
\hline 1972 & 10.812 & 10.890 & 720 & 53.964 & 76.386 & 4.422 \\
\hline 1973 & 10.974 & $11.10 n$ & 720 & 56.738 & 79.532 & 3.146 \\
\hline 1974 & 11.574 & 11.521 & 720 & 59.299 & 83.114 & 3.582 \\
\hline 1975 & 12.102 & 12.217 & 720 & 62.495 & 87.534 & 4.420 \\
\hline 1976 & 12.921 & 13.247 & 745 & 67.203 & 93.846 & 6.312 \\
\hline 1977 & 13.625 & 13.465 & 1.070 & 70.057 & 98.217 & 4.371 \\
\hline 1978 & 14.122 & 13.596 & 1.313 & 72.802 & 101.833 & 3.616 \\
\hline 1979 & 14.669 & 13.912 & 1.333 & 76.344 & 106.258 & 4.425 \\
\hline 1980 & 15.032 & 13.953 & 1.333 & 79.046 & 109.364 & 3.106 \\
\hline
\end{tabular}




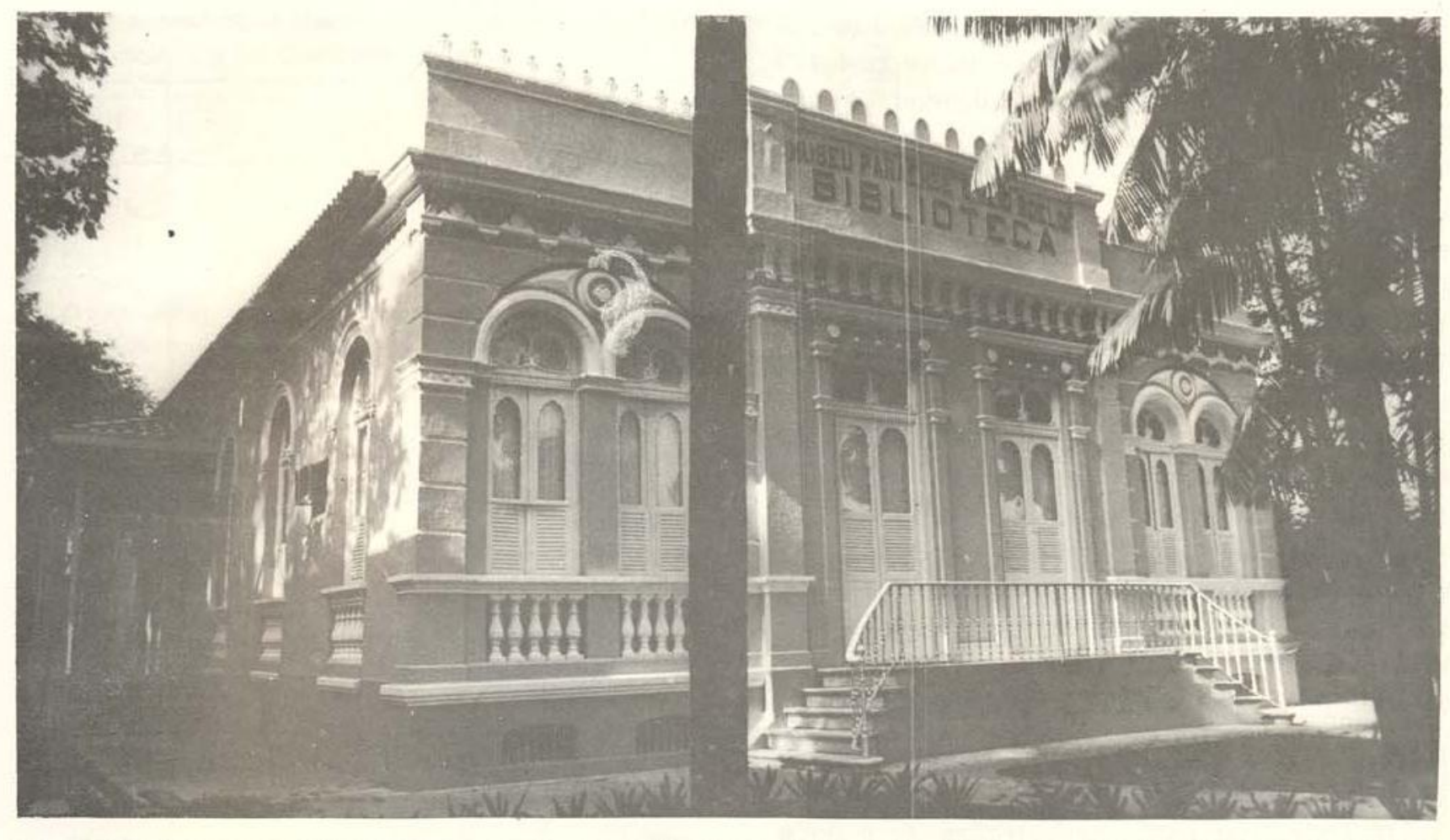

Fig. 1 - Fachada do prédio da Biblioteca.

Por esses dois relatórios, dos quais foram retirados os trechos acima, percebe-se o interesse do $\mathrm{CNPq}$ em dinamizar a Biblioteca, tornando-a um centro vivo de apoio à pesquisa, tanto pela organização do material bibliográfico que permite sua utilização adequada e facilita o acesso às informações, como pela formação de recursos humanos especializados, para os serviços técnicos de armazenamento e recuperação de informações bibliográficas, indispensáveis a qualquer biblioteca ou centro de documentação e informação.

\section{BASE FISICA}

O edifício que serve de sede para a Biblioteca sofreu recentemente mais uma reforma para abrigar material bibliográfico e serviços. Trata-se de uma antiga residência, adaptada para estanteria, saläo de leitura, e salas de trabalho. Como o espaço oferecido por este prédio torna-se cada vez mais insuficiente, está em andamento um projeto de construção de uma nova sede na área de terreno cedida pela EMBRAPA, com espaço para acomodar mais convenientemente a Biblioteca.

\section{ACERVO BIBLIOGRÁFICO}

A Biblioteca dn Museu vem se formando ao longo dos seus 86 anos de existência. Mesmo atravessando fases críticas quanto a recursos humanos e financeiros, consegue hoje reunir um acervo bastante significativo de obras consideradas raras, cujo altíssimo valor histórico e científico suplanta qualquer avaliação, em termos financeiros, que se lhes possa atribuir. A coleção de 131 in-folios inclui as viagens de Humboldt, Spix, e a Flora de Mar. tius, entre outros. Diversos trabalhos de Barbosa Rodrigues e de Castelnau, Crevaux e Coudreau, também compõem a valiosa Coleção Especial da Biblioteca.

A partir de 1955, o crescimento do acervo bibliográfico vem se fazendo de maneira ordenada, com aquisições utilizando verbas específicas, ou pelo método do intercâmbio de publicações. Orientado por uma seleção visando as pesquisas desenvolvidas pelo Museu nos campos das Ciências Naturais e Antropológicas, e procurando sempre reunir, tanto quanto possível, material informativo sobre a Amazônia. 
Existem atualmente na Biblioteca 109.364 documentos, entre os quais se incluem 4.172 títulos de periódicos especializados, sendo 1.274 correntes. (Quad. 1 e 2).

\section{PUBLICAÇÕES}

Contribuiu de mañeira definitiva para o desenvolvimento da Biblioteca a retomada das publicações, não só para o crescimento do acervo bibliográfico - desde aquela época $65 \%$. vem sendo adquirido por permuta com nossas publicações - mas também para devolver a ela a projeção internacional e o lugar que havia conquistado entre as bibliotecas especializadas mais importantes do pais, o que, por falta de recursos, estava prestes a perder. (Quadros 3 e 4 ).

Cada fascículo publicado é remetido a instituições que possam oferecer outra publicação especializada em troca. Atualmente, 3.245 endereços estāo cadastrados, para onde são feitas remessas regulares. (Quad. 5) .
QUADRO 2 - Acervo bibliográfico: periódicos especia. lizados

\begin{tabular}{l|r}
\hline \multicolumn{1}{c|}{ Assuntos } & Títulos \\
\hline $\begin{array}{l}\text { Assuntos Gerais, Filosofia, } \\
\text { Religião, Ciências Sociais, } \\
\text { Lingüistica }\end{array}$ & \\
Ciências Puras (incluindo & \\
Matemática, Astronomia, & \\
Fisica, Quimica) & 894 \\
Geologia & 309 \\
Paleontologia & 23 \\
Antropologia e Arqueologia & 331 \\
Biologia & 156 \\
Botânica & 318 \\
Zoologia & 384 \\
Ciências Aplicadas (incluindo & \\
Medicina, Engenharia Agricultura, & \\
Administração & 968 \\
Artes, Literatura & 13 \\
História e Geografia & 193 \\
\hline TOTAL & 4.172 \\
\hline
\end{tabular}

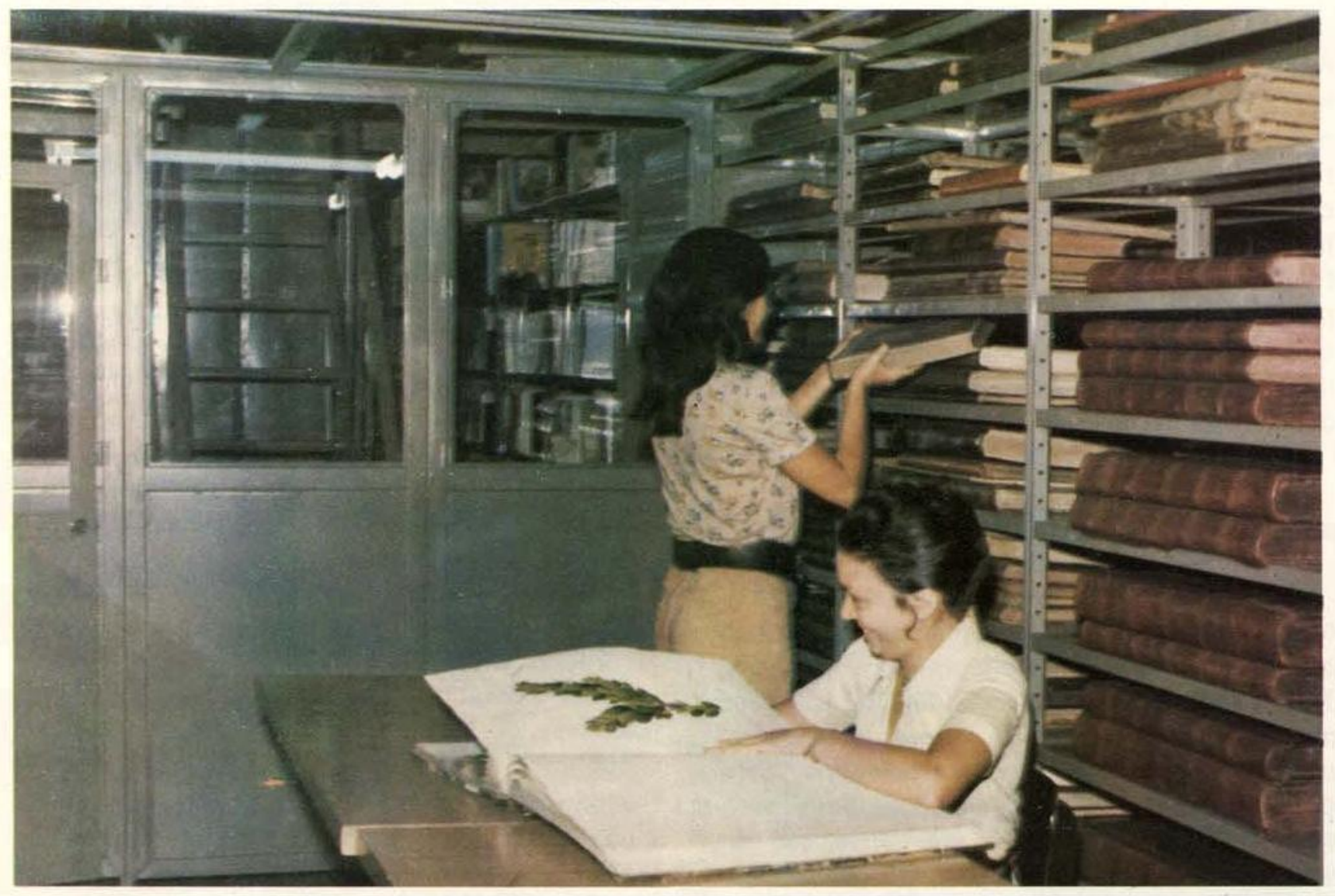

Fig. 2 - Vista parcial da sala de obras raras. 
QUADRO 3 - Publicações Editadas pelo Museu Pa. raense Emílio Goeldi. 1894-1954 (50 anos)

\begin{tabular}{l|r|r}
\hline \multicolumn{1}{c|}{ Títulos } & $\begin{array}{r}\text { Volumes } \\
\text { Publicados }\end{array}$ & $\begin{array}{c}\text { Páginas } \\
\text { Impressas }\end{array}$ \\
\hline Boletim & 10 & 4.707 \\
Memórias & 4 & 280 \\
Arboretum Amazônico & 1 & 40 \\
Aibum das Aves Amazônicas & 2 & 48 \\
Outros & 7 & 368 \\
\hline TOTAL & 24 & 5.443 \\
\hline
\end{tabular}

QUADRO 4 - Publicações Editadas pelo Museu Paraense Emílio Goeldi. 1955-1980 (25 anos)

\begin{tabular}{l|r|r}
\hline \multicolumn{1}{c|}{ Títulos } & $\begin{array}{r}\text { Volumes } \\
\text { Publicados }\end{array}$ & $\begin{array}{r}\text { Páginas } \\
\text { Impressas }\end{array}$ \\
\hline Boletim (Série Antiga) & 2 & \\
Boletim Nova Série & 252 & 8.478 \\
Publicações Avulsas & 35 & 3.891 \\
Guias & 4 & 250 \\
Outros & 3 & 73 \\
\hline TOTAL & 296 & 12.692 \\
\hline
\end{tabular}

QUADRO 5 - Endereços Cadastrados para Permuta

\begin{tabular}{l|r|r|r}
\hline $\begin{array}{l}\text { Publicações do Museu } \\
\text { (Assuntos) }\end{array}$ & Brasil & Exterior & Total \\
\hline Antropologia & 397 & 517 & 914 \\
Botânica & 363 & 469 & 832 \\
Geologia & 298 & 386 & 684 \\
Zoologia & 348 & 467 & 815 \\
\hline TOTAL & 1.406 & 1.839 & 3.245 \\
\hline
\end{tabular}

Como exemplo da importâricia deste intercâmbio, apresentamos $\alpha$ resumo das aquisições do ano de 1980, demonstrando as proporções de $8 \%$ de doações recebidas, $27 \%$ de aquisições por compra e $65 \%$ por permuta (Quad. 6).
FORMAÇÃO DE RECURSOS HUMANOS

A iniciative de promover um curso inten. sivo de técnicas biblioteconômicas, para suprir as necessidades imediatas de pessoal para trabalhar na organização da Biblioteca, reuniu, em 1957, 21 elementos de 16 instituições locais além do Museu, todos eles responsáveis pelo funcionamento das bibliotecas daqueles órgãos, e que, entretanto, não possuíam nenhuma formação para assumir tais responsabilidades. O curso promovido pelo Museu trouxe uma contribuição valiosa para a formação de recursos humanos especializados, inclusive para a Universidade que naquela época não tinha curso de biblioteconomia nem contava com profissionais em seu quadro funcional. Até pouco tempo, eram recebidos na Biblioteca do Museu, estagiários de biblioteconomia da UFPA, para cumprimento de crédito curriculares.

\section{PARTICIPAC̣ÃO EM PROGRAMAS NACIONAIS}

A participação em programas a nível nacional vem merecendo especial atenção da Biblioteca, desde o início de sua reorganização. Entre estes estão os implantados pelo Instituto Brasileiro de Bibliografia e Documentação (IBBD), hoje Instituto Brasileiro de Informaçäc em Ciência e Tecnologia (IBICT): Sistema de Aquisição Planificada; Sistema de Intercâmbio de Catalogação; Sistema de Informações Técnico-Científicas; Catálogo Coletivo Nacional (CCN); Sistema Integrado de Automação de Bibliografias Especializadas (SIABE). E o Sistema Biblioteca Nacional de Agricultura (BINAGRI), desenvolvido pela Empresa Brasileira de Pesquisa Agropecuária (EMBRAPA). De todos esses sistemas e programas, a Biblioteca do Museu participa como colaborador e usuário.

\section{SITUACĀO ATUAL}

Atualmente a Biblioteca tem seus serviços estruturados em 17 setores agrupados em 5 seções. 
QUADRO 6 - Aquisições em 1980

\begin{tabular}{|c|c|c|c|c|c|c|c|c|c|}
\hline $\begin{array}{l}\text { Procedên- } \\
\text { cia }\end{array}$ & Brasil & $\begin{array}{l}\text { Outros } \\
\text { Países da } \\
\text { América } \\
\text { do Sul }\end{array}$ & $\begin{array}{l}\text { América } \\
\text { do Norte }\end{array}$ & Europa & Asia & Africa & Austrália & Total & $\%$ \\
\hline Compra & 299 & 16 & 285 & 256 & - & - & - & 856 & 27 \\
\hline Doação & 148 & 29 & 58 & 17 & - & - & - & 252 & 8 \\
\hline Permuta & 584 & 141 & 563 & 683 & 40 & 34 & 15 & 2060 & 65 \\
\hline Total & 1031 & 186 & 906 & 956 & 40 & 34 & 15 & 3168 & - \\
\hline$\%$ & 32,5 & 6 & 28,6 & 30,2 & 1,2 & 1,0 & 0,5 & - & 100 \\
\hline
\end{tabular}

\section{BIBLIOTECA}

De acordo com nossos controles estatísticos, a Biblioteca vem tendo um crescimento médio de 3.000 a 4.000 documentos anuais (ver. Quad. 1).

Para manter um acervo dessa dimensão utilizado convenientemente, com a análise de cada documento e indexação em um catálogo que permite a recuperação de todas as informações nele contidas no menor tempo possível, torna-se necessário um quadro de pessoal

\section{QUADRO 7 - Estrutura organizacional da Biblioteca}

\begin{tabular}{|c|c|}
\hline Seções & Setores \\
\hline Biblioteca & $\begin{array}{l}\text { Aquisição; Preparação; Periódi- } \\
\text { cos; Coleção Especial; Circula- } \\
\text { ção-Referência - Empréstimos; } \\
\text { Encadernação }\end{array}$ \\
\hline Bibliografia & $\begin{array}{l}\text { Bibliografia da Amazônia; Le- } \\
\text { vantamentos específicos e a } \\
\text { pedido; Normalização }\end{array}$ \\
\hline $\begin{array}{l}\text { Intercâmbio e } \\
\text { Divulgaçäo }\end{array}$ & $\begin{array}{l}\text { Publicaçōes do Museu, Dupli. } \\
\text { catas, Controle de Expedição }\end{array}$ \\
\hline Reprografia & $\begin{array}{l}\text { Laboratório Fotográfico; Xerox: } \\
\text { Mimeógrafo }\end{array}$ \\
\hline $\begin{array}{l}\text { Serviços Auxiliares } \\
\text { e de apoio }\end{array}$ & $\begin{array}{l}\text { Secretaria; Portaria; Serviços } \\
\text { Gerais }\end{array}$ \\
\hline
\end{tabular}

igualmente extenso. Para suprir este problema, alguns projetos têm sido elaborados solicitando financiamento de fontes diversas. Enquanto se aguarda essa liberação de verba, está sendo trabalhada a coleção de obras raras e Relatórios dos Presidentes da Província do Grão Pará.

A divulgação do acervo e serviços é feita através de um Boletim Bibliográfico, mensal, que atualmente é mimeografado, e tem circulação restrita ao âmbito do CNPq e entidades da Amazônia.

De 1955 a 1980, registram as estatísticas, que foram atendidos 215.808 consultas e 24.653 empréstimos de publicações.

No triênio 1978/1980 foram utilizados os seguintes recursos financeiros.

$\begin{array}{ll}1978 & 1.792 .947,80 \\ 1979 & 2.293 .100,00 \\ 1980 & 7.456 .000,00\end{array}$

\section{BIBLIOGRAFIA}

A partir de 1964 foi iniciado o levantamento da Bibliografia de Geologia da Amazônia. Deste trabalho, já resultaram duas publicações editadas em 1969 e 1980 respectivamente, na série Publicações Avulsas do Museu Paraense Emílio Goeldi :

Bibliografia e Indice da Geologia da Amazônia Legal Brasileira, 1961/1964. Belém, Museu Paraense Emílio Goeldi, 1969. 291 p. (Publicação Avulsa, 11). 


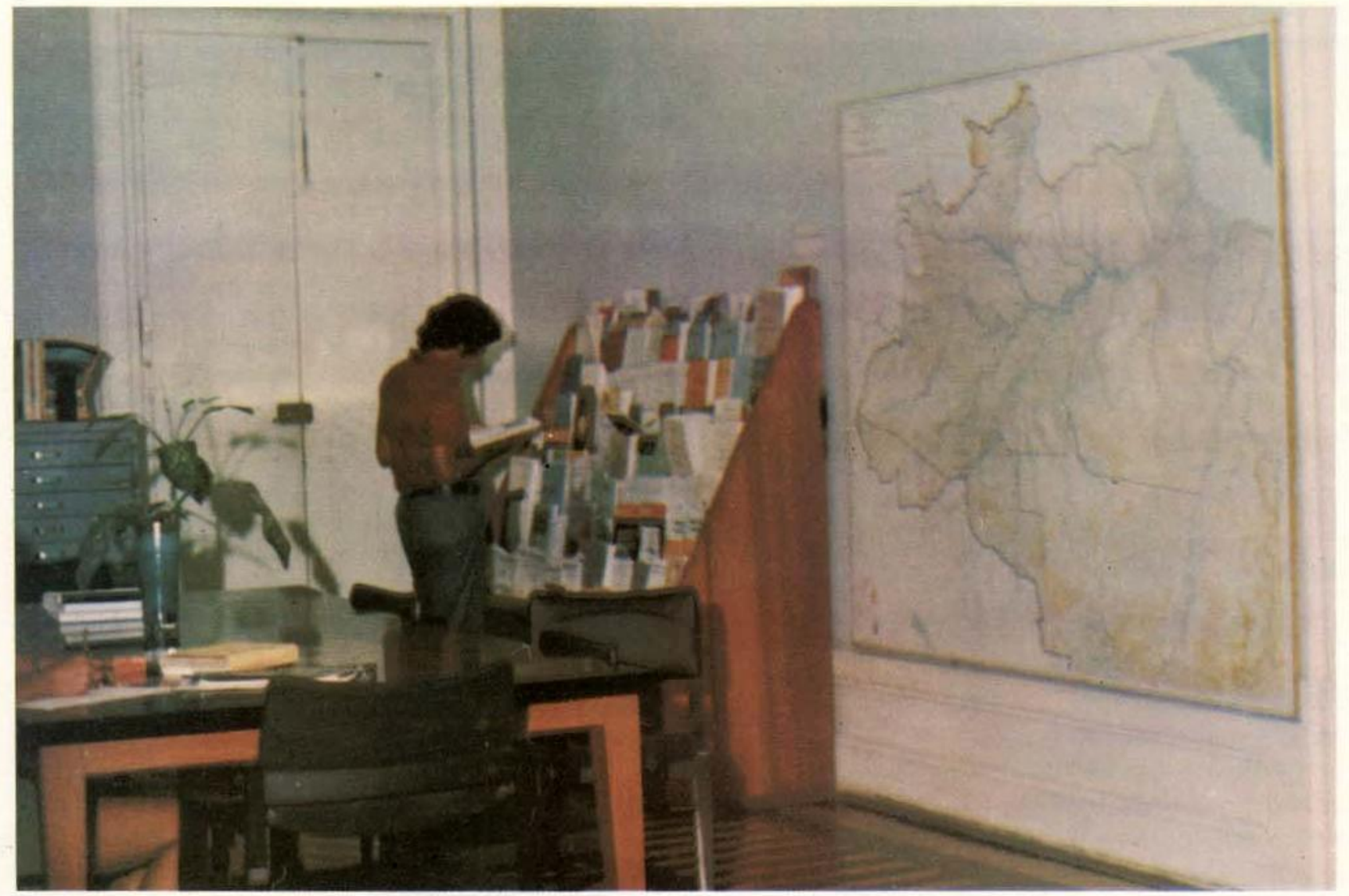

Fig. 3 - Detalhe do salăo de leitura.

Bibliografia e Indice da Geologia da Amazônia Legal Brasileira, 1965/1975. Belém, Museu Paraense Emílio Goeldi, 1980. 176 p. (Publicação Avulsa, 35).

Atualmente o programa mais importante desta Seção é a Bibliografia da Amazônia.

Este projeto resultou de uma reunião em que participaram todos os representantes dos centros de documentação do CNPq no Rio de Janeiro, em 1978, e tem como objetivo coletar e divulgar a bibliografia da Amazônia, utilizando o Sistema Integrado de Automação de Bibliografias Especializadas (SIABE)/IBICT. O Museu Goeldi, através da Biblioteca, é responsável pelo levantamento dos assuntos de sua área de especialização, especialmente os trabalhos existentes na Biblioteca.

Ainda neste programa, está sendo estudada a construção de um vocabulário controlado para a recuperação dos itens da bibliografia da Amazônia.

INTERCAMBIO E DIVULGAÇAO

A Biblioteca através do setor de Intercâm. bio e Divulgação é responsável pelo armazenamento e distribuição das publicações editadas pelo Museu, quer esta seja por venda, doação ou permuta por outras semelhantes.

Em 1980 deram entrada 21.000 exemplares de 9 Boletins publicados e foram expedidos 12.673 exemplares por permuta.

$O$ quadro a seguir demonstra a entrada das publicações em 1980 e o valor destas em dinheiro.

Nesse mesmo ano, saíram publicaçōes num total de Cr\$ 228.987,00 dos quais Cr\$ 198.032,00 correspondem a doações e permutas. 
QUADRO 8 - Entrada de publicaçōes em 1980

\begin{tabular}{ll|c|r}
\hline \multicolumn{1}{c|}{ Publicações } & & $\begin{array}{r}\text { N. de } \\
\text { Exemplares }\end{array}$ & \multicolumn{1}{c}{ Valor } \\
\hline Bol. Antropologia & n. 75 & 1.500 & $8.160,00$ \\
Bol. Geologia & n. 22 & 1.000 & $8.400,00$ \\
Bol. Zoologia & n. 99 & 1.000 & $8.160,00$ \\
Bol. Zoologia & n. 100 & 1.000 & $32.328,00$ \\
Bol. Zoologia & n. 101 & 1.000 & $5.100,00$ \\
Bol. Zoologia & n. 102 & 1.000 & $13.788,00$ \\
Bol. Zoologia & n. 103 & 1.000 & $10.922,40$ \\
Publ. Avulsas & n. 34 & 1.500 & $68.325,00$ \\
Publ. Avulsas & n. 35 & 1.000 & $80.000,00$ \\
Ind. Zoologia & 81.100 & 1.000 & $2.040,00$ \\
Folheto Museu Goeldi & 10.000 & $50.000,00$ \\
& & & \\
\hline & & 21.000 & $295.005,40$ \\
\hline
\end{tabular}

\section{CONCLUSÃO}

O Museu Goeldi, como instituição científica não pode prescindir de uma coleção bibliográfica que sirva de apoio às pesquisas. Desta maneira, sua Biblioteca reune hoje um acervo de valor inestimável tanto histórico como científico. A manutenção dessa coleção, sua conservação e utilização adequada se fazem a um custo relativamente alto, e uma interrupção no seu desenvolvimento acarreta perdas, muitas vezes irrecuperáveis. A atitude do CNPq, em tomar a seu encargo o Museu Goeldi, trouxe à Biblioteca, a possibilidade de retomar suas atividades e procurar cumprir suas finalidades junto à comunidade cientifica nacional e inter- nacional, através do intercâmbio de publicações, e de contribuir de maneira efetiva para o desenvolvimento científico da Amazônia.

\section{SUMMARY}

The Library was founded in 1894 to provide the bibliographic support to the researches carried out in Museu Goeldi, and, as a consequence of that, has accompanied the phases of increase an decrease of this institution. Since 1954, because of the Accord signed with the Para State Government, Museu Goeldi was trasfered to the administrative area of CNPq, as a subordinate department of INPA, the Library was then leorganized, obtaining larger personnel and financial means, taking a new impulse of growth to regain its position among the best in the country. Now when the $\mathrm{CNPq}$ 30th anniversary is celebrated, the Library presents an expressive and specialized colletion (109.364 documents), partakes of national and international programs of cooperation, puts into practice reciprocal exchanges with 3.245 both foreign and domestic institutions. And, besides its privative finality as a support to the researches carried out in Museu Goeldi, the Library has an average of 8.300 annual users' requests.

\section{REFERENCIAS BIBLIOGRAFICAS}

\section{GALVÃO, Clara Maria}

1955 - Relatório agosto-setembro e Plano de trabalho, 1955. $5 \mathrm{p}$. (datilograf.).

- Relatório (Biblioteca): agosto-dezembro. 1955. 4 p. (datilograf.).

1975 - Como usar a biblioteca. Belém, Museu Paraense Emílio Goeldi. 24 p. il. (Guia, 3).

MUSEU PARAENSE EMILIO GOELDI. Biblioteca

1956-1980 - Relatório anual. (datilograf.).

\section{A PENDICE \\ Publicações editadas pelo Museu Paraense Emílio Goeldi (1955/1980).}

BOLETIM DO MUSEU PARAENSE EMILIO GOELDI. NOVA SERIE, ANTROPOLOGIA

01 - HILBERT, Peter Paul. Contribuiçăo à Arqueologia do Amapá - Fase Aristé. Belém, 1957. 37 p., il.

02 - CROCKER, William. Os indios Canelas de hoje - Nota prévia. Belém, 1958. 9 p.

03 - OLIVEIRA, Roberto Cardoso de. A situação atual dos Tapirapé. Belém, 1959. $11 \mathrm{p}$.
04 - FRIKEL, Protásio. Agricultura dos indios Mundurukú. Belém, 1959. 36 p., il.

05 - SILVA, Armando Bordalo da. Contribuição ao estudo do folclore Amazônico na Zona Bragantina. Belém, 1959. 76 p., 5 est.

06 - HILBERT, Peter Paul. Urnas funerárias do Rio Cururú, Alto Tapajós. Belém, 1958. 13 p., il.

07 - GALVÃO, Eduardo. Aculturação indígena no Rio Negro. Belém, 1959. 60 p., est. 
08 - GALVÃO, Eduardo. Áreas culturais indigenas do Brasil; 1900-1959. Belém, 1960. 41 p.. mapas.

09 - FRIKEL, Protásio. Os Tiriyós. Notas preliminares. Belém, 1960. 16 p., est.

10 - MOREIRA NETO, C.A. A cultura pastoril do Pau-D'Arco. Belém, 1960. 112 p., est.

11 - ARNAUD, Expedito. Breve informação sobre os indios Asurini e Parakanan; Rio Tocantins, PA. Belém, 1961. 22 p.

12 - FRIKEL, Protásio. Mori - A festa do rapé. Indios Kachúyana; Rio Trombetas. Belém, 1961. 34 p., est.

13 - BARNER, Horace. O índio Kayapó em seu acampamento. Belém, 1961. $51 \mathrm{p}$.

14 - DERBYSHIRE, Desmond. Notas comparativas sobre três dialetos Karibe. Belém, 1961. $10 \mathrm{p}$.

15 - FIGUEIREDO, Napoleão. A festa dos "Coletores" entre os Aramagóto. Belém, 1961. 19 p., est., mapa.

16 - FRIKEL, Protásio. Onematuipe - Os transformados. Belém, 1961. 15 p., 2 est.

17 - FRIKEL. Protásio. Fases culturais na área do Tumucumaque. Belém, 1961. 16 p., mapa, tab.

18 - DINIZ, Edson Soares. Os Kayapó-Gorotire. Aspectos sócio-culturais do momento atual. Belém, 1962. 40 p., 2 tab., 2 mapas, 10 est., 1 qd.

19 - LEACOCK, Seth. Economic life of the Maué Indians. Belém, 1964. 30 p., mapa, il.

20 - ARNAUD, Expedito. Notícias sobre os índios Gaviōes do Oeste, Rio Trombetas, PA. Belém, 1964. 35 p., mapa, il.

21 - HEINRICHS, Arlo L. Os fonemas do Mura-Pirahã. Belém, 1964. 9 p.

22 - MIGLIAZZA, Ernesto. Notas sobre a organização social dos Xiriâna do rio Uriricaá. Belém, 1964. 19 p., mapa, 4 tab.

23 - LAS CASAS, Roberto Décio de. Indios e brasileiros no vale do rio Tapajós. Belém, 1964. 31 p., est., mapa, tab.

24 - GALVÃO, Eduardo \& SIMŌES, Mário F. Notícia sobre os índios Txikão, Alto Xingu. Belém, 1965. 23 p., 12 est., mapa.

25 - MIGLIAZZA, Ernesto. Fonologia Máku. Belém, 1965. 17 p., mapa, tab.

26 - MAC DONALD, J. Frederich. Some considerations about Tupi-Guarani kinship structures. Belém, 1965. 20 p., il., tab.

27 - FIGUEIREDO, Napoleão. A cerâmica arqueológica do rio Itacaiúnas. Belém, 1965. 17 p., 4 est., 2 map., 2 tab.
29 - DINIZ, Edson Soares. Braves notas sobre o sistema de parentesco Makuxí. Belém, 1965. 16 p., mapa, 3 tab.

29 - MigliAZZA, Ernesto. Notas fonológicas da língua Tiriyó. Belém, 1965. 13 p.

30 - ARNAUD, Expedito. Os índios Galibí do rio Oiapoque; tradiçāo e mudança. Belém, 1966. 52 p., 8 est., mapa.

31 - DNIZ, Edson Soares. O perfil de uma situação interétnica: os Makuxí e os regionais do Roraima. Belém, 1966, 31 p., 5 est., mapa.

32 - MIGLIAZZA, Ernesto. Esboço sintático de um corpus da língua Máku. Belém, 1966. 38 p.

33 - ARNAUD, Expedito. O parentesco entre os índios Galibi do rio Oiapoque. Belém, 1968. 11 p., 5 tab.

34 - DINIZ, Edson Soares. A terminologia de parentesco dos indios Wapitxâna. Belém, 1968. 11 p., mapa, 3 tab.

35 - OliveirA, Adélia Engrácia de. Os índios Juruna e sua cultura nos dias atuais. Belém, 1968. 25 p., 3 est.

36 - ARNAUD, Expedito. Referência sobre o sistema de parentesco dos índios Palikúr. Belém, 1968. 21 p., 3 tab.

37 - SHAPIRO, Judith. Tapirapé Kinship. Belém, 1968. 32 p., 5 tab.

38 - SHAPIRO, Judith. Cerimonial redistribution in Tapirapé society. Belém, 1968. $20 \mathrm{p}$.

39 - DINIZ, Edson Soares. Aspectos das relaçōes sociais entre os Yanomamo do rio Catrimâni. Belém, 1969. 18 p., 3 est., mapa, tab.

40 - ARNAUD, Expedito. Os índios da regiāo do Uaçá (Oiapoque) e a proteção oficial brasileira. Belém, 1969, 37 p., 3 est., mapa.

41 - OlIVEIRA, Adélia \& GALVÃO, Eduardo. A cerâmica dos índios Juruna (rio Xingu). Belém, 1969. 19 p., est.

42 - ARNAUD, Expedito \& GALVÃO, Eduardo. Notícias sobre os indios Anambé (rio Cakari, PA.). Belém, 1969, 11 p., 6 est.

43 - WALLACE, Ruth. Notas fonológicas da língua Kaxuyâna. Belém, 1970. 20 p.

44 - ARNAUD, Expedito. O Xamanismo entre os indios da região de Uaçá-Oiapoque, Território do Amapá. Belém, 1970. 22 p., est.

45 - Oliveira, Adélia Engrácia de. Parentesco Juruna. Belém, 1970, 44 p., 2 tab., 6 figs.

46 - FURTADO, Lourdes G. O fenômeno da grilagem da cidade de Belém - Nota prévia. Belém, 1971. 25 p., il., 4 qd., est.

47 - ARNAUD, Expedito. Os indios Oyampix e Emerilon (rio Oiapoque); referências sobre o passado e o presente. Belém, 1971. 28 p. 
48 - CORREA, Conceição \& SIMÕES, Mário F. Pesquisas arqueológicas na regiāo do Salgado, PA. Belém, 1971. $30 \mathrm{p}$.

49 - ARNAUD, Expedito. A ação indigenista no sul do Pará. 1940-1970. Belém, 1971. 25 p.

50 - SILVEIRA, Isolda M. Aspectos sócio-econômicos de Oriximiná (Sede) - Nota Prévia. Belém, 1972. 37 p., 4 est., 1 mapa, 1 plan. ta.

51 - SÁ, Samuel. Tradição oral e criatividade em Arca dos Engenhos - Pará. Nota Prévia. Belém, 1972. 30 p., il.

52 - FURTADO, Lourdes G. \& SANTANA, M. da Conceição. Vila da Barca. Belém, notas sobre grilagem. Belém, 1972. 18 p., il.

53 - ARNAUD, Expedito \& ALVES, Ana Rita. A extinção dos índios Kararaó (Kayapó) - Baixo Xingu, PA. Belém, 1974. 16 p.

54 - ARNAUD, Expedito. Os índios Mundurukú e o serviço de proteção aos indios. Belém, 1974. $60 \mathrm{p}$.

55 - BRABO, Maria José C. Grupos domésticos em Arca dos Engenhos. Belém, 1974. 22 p., il.

56 - OLIVEIRA, Adélia Engrácia de. A terminologia de parentesco Baniwa - 1971. Belém, 1975. $34 \mathrm{p} .$, il.

57 - VELTHEM, Lúcia H. van. Plumária Tukano. Uma tentativa de análise. Belém, 1975. 29 p., il.

58 - OLIVEIRA, Adélia Engrácia de. São João - Povoado do rio Negro (1972). Belém, 1975. $56 \mathrm{p}$.

59 - CORTEZ, Roberto. O indio na consciência urbana. Belém, 1975. $18 \mathrm{p}$.

60 - ARNAUD, Expedito \& ALVES, Ana Rita. A terminologia de parentesco entre os índios Galibi e outros grupos Karib. Belém, 1975. 18 p., il., qd.

61 - CORTEZ, Roberto. Diálogo cerimonial e diálogo mitológico entre os Tiriyó. Belém, 1975. 25 p.

62 - SIMÕES, Mário F. Nota sobre duas pontas-deprojétil da bacia do Tapajós, PA. Belém, 1976. 14 p.

63 - ARNAUD, Expedito; CORTEZ, Roberto \& ALVES, Ana Rita. A terminologia de parentesco dos indios Gaviōes do Oeste (Parakatêyê) - Tocantins, PA. Belém, 1976. 15p., il.. 1 qd.

64 - VELTHEM, Lúcia H. van. Representações gráficas Wayâna-Aparaí. Belém, 1976. 19 p., il.

65 - RODRIGUES, Ivelise \& OLIVEIRA, Adélia Engrácia de. Alguns aspectos da ergologia Mura-Pirahã. Belém, 1977. 47 p., il.

66 - OlIVEIRA, Adélia Engrácia de. A terminologia de parentesco Mura-Pirahã. Belém, 1978. 33 p., il.
67 - FURTADO, Lourdes Gonçalves. Aspectos históricos e econômicos de Marapanim-Nordeste Paraense. Belém, 1978. 32 p., il.

68 - CROCKER, William H. Estórias das épocas de pré e pós pacificação dos Ramkókamera e Apaniekra-canelas. Belém, 1978. 30 p., il.

69 - FLEMING-MORAN, Millicent \& MORÁN, Emílio F. $O$ surgimento de classes sociais numa comunidade planejada para ser igualitária. Belém, 1978. 35 p., il.

70 - FURTADO, Lourdes G.; SOUZA Ruth Cortez de \& BERG, Maria Elisabeth van den. Notas sobre uso terapêutico de plantas pela população cabocla de Marapanim, Pará. Belém, 1978. $31 \mathrm{p}$.

71 - ARNAUD, Expedito. Notícias sobre os índios Araweté, Rio Xingu, Pará. Belém, 1978. 20 p., il.

72 - OlIVEIRA. Adélia Engrácia de. Depoimentos Baniwa sobre as relações entre indios e civilizados no Río Negro. Belém, 1979. 31 p., il.

73 - BRABO, Maria José C. Palmiteiros de Muaná - estudo sobre o processo de produção no beneficiamento do açaizeiro. Belém, 1979. 29 p., il.

74 - SILVEIRA, Isolda Maciel da. Formas de aviamento num povoado pesqueiro da Amazônia. Belém, 1979. 24 p., il.

75 - HILBERT, Peter Paul \& HILBERT, Klaus. Resultados preliminares da pesquisa arqueológica nos rios Nhamundá e Trombetas, Baixo Amazonas. Belém, 1980. 11 p., il.

76 - VELTHEM, Lúcia Hussak van. O Parque indígena de Tumucumaque. Belém, 1980. 31 p.

77 - BRABO, Maria José Carvalho. Pescadores, geleiros, fazendeiros. Os conflitos da pesca em Cachoeira do Arari. Belém, 1981. 22 p., il.

78 - SIMÕES, Mário F. Coletores-pescadores ceramistas do litoral do Salgado (Pará). Belém, 1981, 26 p., il.

\section{BOLETIM DO MUSEU PARAENSE EMILIO GOELDI. NOVA SÉRIE, AVULSA}

01 - (Número único da série, editado em homenagem póstuma a Walter A. Egler, reunindo 4 trabalhos sobre limnologia, de diferentes autores). Belém, 1962. 83 p., il.

BOLETIM DO MUSEU PARAENSE EMILIO GOELDI.

\section{NOVA SÉRIE, BOTÂNICA}

01 - SMITH, B. Três bromeliáceas novas do Museu Paraense Emilio Goeldi. Belém, 1958. 4 p., il. 
02 - SMITH, Lyman B. \& DOWNS, Robert J. Xyridáceas do Herbário do Museu Paraense Emílio Goeldi. Belém, 1959. 9 p., il.

03 - MOLDENKE, Harold N. Eriocaulaceae Novae collectae Serra do Cachimbo, Pará, Brasil. Belém, 1960. 4 p.

04 - EGLER, Walter S. Contribuição ao conheci. mento dos campos da Amazônia. I - Os campos do Ariramba. Belém, 1960. 36 p., 4 est., diagrs.

05 - TAKEUCHI, Masayuki. O Gênero Schizaea na Amazônia. Belém, 1960, 26 p., 5 est., il.

06 - TAKEUCHI, Masayuki. A estrutura da vegetação na Amazônia. I. A mata pluvial tropical. Belém, 1960, 17 p., 8 est., 12 tab.

07 - TAKEUCHI, Masayuki. A estrutura da vegetação na Amazônia. II - As savanas do norte da Amazônia. Belém, 1960. 14 p., 4 est.

08 - TAKEUCHI. Masayuki. A estrutura da vegetação na Amazônia. III - A mata de campina na região do Rio Negro. Belém, 1960, 13 p., 4 est.

09 - PIRES, João Murça \& CAVALCANTE, Paulo B. Três novas espécies da flora Amazônica (Ebenacea). Belém, 1960. 4 p., 5 est.

10 - SIOLI, Harald. Estratificação radicular numa caatinga baixa do alto Rio Negro. Belém, 1960. 9 p., 3 est.

11 - CUATRECASAS, José. Burseraceae Brasiliae Novae. Belém, 1961. 9 p., 3 est.

12 - SMITH, Lyman B. Uma nova Bromélia do Estado do Amazonas. Belém, 1961, 2 p., 1 est.

13 - EGLER, Walter A. \& PIRES, Joåo Murça. Notas sobre a redescoberta de Hevea camporum Ducke. Belém, 1961. 6 p., 1 est.

14 - EGLER, Walter A. O Gênero Gleasonia (Rubiacea) na Amazônia. Belém, 1961. 7 p., 1 est.

15 - RODRIGUES, William A. Aspectos fitossociológicos das caatingas do rio Negro. Belém. 1961. 41 p., 1 est.

16 - RODRIGUES, William A. Contribuição ao estudo da flora manauense. Belém, 1962. 11 p., 2 est.

17 - GESSNER, Fritz. A abertura das flores de Victoria Régia, em relação à luz. Belém, 1962. 13 p.., il.

18 - EGLER, Walter A. Adolpho Ducke, traços biográficos, viagens e trabalhos. Belém, 1963. 129 p.

19 - RODRIGUES, William A. Estudo de 2,6 hectares de mata de terra firme da serra do $\mathrm{Na}$ vio, Território do Amapá. Belém, 1963. 22 p., 2 figs., 7 grf., 11 qds.
20 - CAVAlCANTE, Paulo B. Contribuição ao conhecimento do gênero Diospyros Dalech (Ebenaceae) na Amazônia. Belém, 1963, $54 \mathrm{p}$.

21 - CAVALCANTE, Paulo B. Nova contribuição ao conhecimento do gênero Diospyros Dalech (Ebenaceae) no Brasil. Belém, 1963. 15 p., 2 est.

22 - CAVALCANTE, Paulo B. Duas novas espécies do gênero Diospyros Dalech. (Ebenaceae) na Amazônia. Belém, 1966. 5 p., 2 est.

23 - PAULA, José Elias de. Contribuição ao estudo da nervação foliar das compostas dos Cerrados - III: Tribo Astereae. Belém, 1966. 13 p., 11 est.

24 - FERREIRA, A.F. \& SALGADO-LABOURIAU, M.L. Pollen grains of plants of the "Cerrado". XV - Aquifoliaceae, Flacourtiaceae and $\mathrm{Me}$ liaceae. Belém, 1966. 11 p., 3 est., 2 tab.

25 - SAlgAdO-LABOURIAU, M.L. \& GUSMAN, A. Barioni. Pollen grains of plants of the "Cerrado". XVI - Malvaceae. Belém, 1967. 12 p., 3 est., 1 tab.

26 - CAVAlCANTE, Paulo B. O guaraná Paulinia cupana var. sorbilis em estado provavelmente espontâneo, no planalto de Santarém, Pará. Belém, 1967. 5 p.

27 - PAULA, José Elias de. Estudos sobre Vochysiaceae - 1. Contribuição ao conhecimento da morfologia foliar de Erisma uncina. tum Warming. E. calcaratum (Link) Warming e E. splendens Stafleu, da Amazônia. Belém, 1967. 12 p., 21 est., 2 tab.

28 - PAULA, José Elias de. Estudos sobre Vochysiaceae - II. Contribuição para o conhecimento dos gêneros Erisma Rudje e Qualea Aublet. Belém, 1967. 9 p., 13 est.

29 - PAULA, José Elias de. Estudos sobre Vochysiacaee - III. Contribuição ao conhecimento de Erisma bicolor Ducke e E. macrophyllum Ducke. Belém, 1967. 7 p., 8 est., 3 tab.

30 - CAVALCANTE, Paulo B. Contribuição ao estudo dos corpos silicosos das gramineas Amazônicas. 1 - Panicoideae (Melinideae, Andropogoneae e Tripsaceae). Belém, 1968. 11 p., 26 est.

31 - PAULA, José Elias de. Estudos sobre Vochysiaceae - IV. Contribuição para o conhecimento do gênero Vochysia Poiret e Erisma Rudge, da Amazônia. Belém, 1969. 23 p., 11 est., 2 tab.

32 - SALGADO-LABOURIAU, M.L.; CARVALHO, L. D'A. Freire de; CAVALCANTE, Paulo B. Pollen grains of plants of the "Cerrado". XXI - Ebenaceae, Nyctaginaceae, Rhamnaceae and Solonaceae. Belém, 1969, 12 p., il. 1 est. 
33 - BARROSO, G.M. Sobre o colorido vermelhopurpúreo de Vernonia erythrophila DC. Belém, 1970. 7 p., il.

34 - COE-TEIXEIRA, Beulah. Algumas espécies novas de Lauráceas da Amazônia. Belém, 1970, 15 p., 5 est.

35 - CAVAlCANTI, Laise de Holanda. Coleção de Mixomicetos do Museu Paraense Emílio Goeldi. Belém, 1970. 5 p.

36 - AYRES, Manuel; BARROS, Regina Maria; SALZANO, Francisco M. \& CAVALCANTE, Paulo B. Hemaglutininas e hemolisinas em plantas da região amazônica. Belém, 1970. 8 p., 4 tab.

37 - CAVAlCANTE, Paulo B. Centrosema carajasense, uma nova leguminosa da Amazônia. Belém, 1970. 4 p., il.

38 - BERG, Maria Elisabeth van den. Uma espécie e duas variedades novas de Guttiferae da Amazônia. Belém, 1970. 6 p., 2 est.

39 - CAVAlcante, Paulo B. \& CARVAlho, Maryan J.C. O gênero Poraqueiba (Icacinaceae) na Amazônia. Belém, 1971. 10 p., 3 est.

40 - BERG, Maria Elisabeth van den. Notas sobre Vismia guianensis (Aubl.) Choisy e suas novas variedades. Belém, 1971. 13 p., 3 est.

41 - VASCONCELOS, M.C. \& BERG, Elisabeth van den. Morfologia dos esporos de pteridófitas amazônicas (typus). Belém, 1971. 4 p.

42 - CARVALHO, Maryan J.C. O pólen em plantas da Amazônia. Gêneros Poraqueiba Aubl. e Ennotum Desv. (Icacinaceae). Belém, 1971. $4 \mathrm{p}$.

43 - ANDRADE, Teresinha A.P. de. O pólen em plantas da Amazônia. Familia Gnetaceae (Gymnospermae). Belém, 1971. $5 \mathrm{p}$.

44 - VASCONCElOS, Normélia C.; CARVALHO, Maryan J.C.; ANDRADE, A.P. de \& BERG, Elisabeth van den. O pólen em plantas da Amazônia. Família Guttiferae. Belém, 1972. $10 \mathrm{p}$.

45 - BAUTISTA, Hortensia Pousada. Duas espécies novas de Sellaginella da Amazônia. Belém, 1974. 3 p., il.

46 - ANDRADE, Teresinha A.P. de. O pólen em plantas da Amazônia; o gênero Dyrsonima Rich (Malpighiaceae). Belém, 1974. 10 p.

47 - BAUTISTA, Hortensia Pousada \& ANDRADE, Teresinha A.P. de. O pólen em plantas da Amazônia. V - Contribuição ao estudo da família Icacinaceae. Belém, 1975. 11 p.

48 - BAUTISTA, Hortensia Pousada; BERG, Elisabeth van den \& CAVALCANTE, Paulo B. Flora Amazônica. I - Pteridófitas. Belém, 1975. $41 \mathrm{p}$.
49 - LEITE, Ångela M.C. O gênero Rauvolfia Plum Ex L. (Apocynaceae) na Amazônia Brasileira. Belém, 1975. $16 \mathrm{p}$.

50 - VILHENA, Raimunda. Anatomia foliar de Gymnospermae da Amazônia Brasileira I - Po. docarpus sellowii Klotzchi. Belém, 1977. 5 p. il.

51 - BERG, Maria Elisabeth van den \& BRITO-OHASHI, Orlandina. Revisão do gênero Bana. ra Aubl. (Flocourtiaceae) na Amazônia Brasileira. Belém, 1978. 8 p.

52 - PIRES, João Murça. Notas de Herbário I. Belém, 1981. 11 p.. il.

\section{BOLETIM DO MUSEU PARAENSE EMÍLIO GOELDI, NOVA SÉRIE, GEOLOGIA}

01 - SIOLI, Harald. Valores de $\mathrm{pH}$ de águas amazônicas. Belém, 1957. 37 p., tab., mapa.

02 - FERREIRA, C. Simōes \& CUNHA, Osvaldo Rodrigues da. Contribuiçăo à paleontologia do Estado do Pará. Notas sobre a Formação Pirabas, com descrição de novos inverte. brados fósseis. I - Mollusca-Gastropoda Belém, 1957. 61 p., 5 est., mapa.

03 - FerReira, C. Simōes \& CUNHA, Osvaldo Rodrigues da. Contribuição à paleontologia do Estado do Pará. Redescrição de novas ocorrências do Dentallun paulini Maury. 1924, na área da Formação Pirabas. II Mollusca-Schaphoda. Belém, 1957. 10 p.. 2 est.

04 - FERREIRA, C. Simões \& CUNHA, Osvaldo Rodrigues da. Contribuição à paleontologia do Estado do Pará. Novos invertebrados fósseis e redescrição de mais duas espécies da Formação Pirabas. III - Molluscę. Gastropoda. Belém, 1957. 33 p., 2 est.

05 - BEURLEN, Karl. Contribuição à paleontologia do Estado do Pará. Crustáceos decápodes da Formação Pirabas. 1 - Arthropoda-Crustaceae. Belém, 1958. 48 p., 4 est.

06 - BEURLEN, Karl. Contribuição à paleontologia do Estado do Pará. Um Balanomorfo da Formação Pirabas. II - Arthropoda-Crustacea. Belém, 1958, 6 p., 1 est.

07 - Oliveira, Paulo E. de. Contribuição à paleon. tologia do Estado do Pará. Um novo Nautiloide da Formação Pirabas. IV. - Mollusca-Cephalopoda. Belém, 1958, 7 p., il.

08 - FERREIRA, Cândido Simões \& CUNHA, Osvaldo Rodrigues da. Contribuição à paleontologia do Estado do Pará. Novas considerações sobre a Formação Pirabas e descriçāo de novos invertebrados fósseis. $\mathrm{V}-(\mathrm{Mol}-$ lusca-Pele cypoda). Belém, 1959, 76 p., il. 
09 - FERREIRA, Cândido Simōes. Contribuição à paleontologia do Baixo Parnaiba, no Estado do Piauí. Formação Pirabas, Mioceno inferior. Belém, 1964. 51 p., est., tab., mapa.

10 - FERREIRA, Cândido Simōes. Contribuição à paleontologia do Estado do Pará. Um novo Xancus da Formação Pirabas. VII - (Mollusca-Gastropoda). Belém, 1964. 8 p., 2 est.

11 - FERREIRA, Cândido Simões. Contribuiçăo à paleontologia do Estado do Pará. Sobre a taxonomia e sistemática de alguns molus$\cos$ da Formação Pirabas. VIII - (Mollusca-Palecypoda). Belém, 1965. 21 p., 2 est.

12 - BARBOSA. Maria Martha. Brizoários do cabonífero do Estado do Pará, Brasil. I Belém, 1965. 5 p., 2 est.

13 - SILVA, Otavio Ferreira da \& LOEWENSTEIN, Pedro. Contribuição à geologia da folha de São Luiz (SA-23), no Estado do Pará. II Novas localidades e razão magnésio cálcio do calcário Pirabas. Belém, 1968. 17 p., tab., mapa.

14 - JUPIASSÚ. Adélia Maria S. Madeira fóssil Humiriacea de Irituia, Estado do Pará. Belém, 1970. 12 p., il., 4 est.

15 - FERREIRA, Cândido Simões. Moluscos do terciário marinho na baía de São Marcos. Maranhão. Belém, 1970. 30 p., 4 est.

16 - SANTOS, Rubens da Silva \& SALGADO, Marise Sardenberg. Contribuição à paleontologia do Estado do Pará. Novos restos de peixes da Formação Pirabas. Belém, 1971. 13 p., 2 est.

17 - FRANCISCO, Benedito Humberto R.; LOEWENSTEIN, Pedro; SILVA, Octavio Ferreira da \& SILVA, Guilherme Galeão. Contribuição à geologia da folha de São Luiz (SA-a3), no Estado do Pará. III - Estratigrafia. IV Recursos minerais. Belém, 1971. 40 p., 5 est., mapa.

18 - BRITO, Inacio Machado. Contribuição à paleontologia do Estado do Pará. Sobre um Balanomorfo da Formação Pirabas. (Crustacea-Cirripedia). Belém, 1972. 3 p., est.

19 - CAMPOS, Dea Regina Bouret. Contribuição à paleontologia do Estado do Pará. Revisāo da família Arcidae, na Formaçāo Pirabas (Mioceno Inferior). $\mathrm{XI}-$ (Mollusca-Bivalvia). Belém, 1974. 34 p., 4 est.

20 - XAVIER, Sonia Zanotti. Contribuição à paleontologia do Estado do Pará. Revisão do gênero Glycymeris da Costa, 1978, da Formação Pirabas (Mioceno Inferior). XII - (Mollusca, Bivalvia). Belém, 1974. 24 p., 2 est.
21 - CARVALHO, R.G. de. Braquiápodes devonianos da Bacia Amazônica. Orthida, Strophomenida Speriferida e Terebratulida. Belém, 1975. 35 p., il.

22 - FERNANDES, Antônio Carlos S. Contribuiçăo à paleontologia do Estado do Pará. Scleractina da Formação Pirabas (Mioceno Inferior) e suas implicações paleoecológicas. Belém, 1979. 33 p.

23 - BRITO, Ignacio Machado. Contribuição à paleontologia do Estado do Pará. A ocorrência de Abertella (Echinoidea Clypeasteroidea) na Formação Pirabas. Belém, 1981. 8 p., il.

24 - FERNANDES, Antonio Carlos Sequeira. Contribuiçâo à paleontologia do Estado do Pará. Um novo Flabellum (Anthozoa-Scleractinia) na Formação Pirabas. Belém, 1981, 7 p., il.

\section{BOLETIM DO MUSEU PARAENSE EMILLIO GOELDI NOVA SÉRIE, ZOOLOGIA}

01 - NOVAES, Fernando \& CARVALHO, Cory T. de. Observações sobre a nidificaçầo cio Glaucis hirsuta (Gmelin). Trochilidae Aves. Belém, 1957. 11 p., 2 est., 2 tab.

02 - CARVAlHO, Cory T. de. Notas ecológicas sobre Volatinia jacarina (Passeres Frigilidae). Belém, 1957. $10 \mathrm{p}$.

03 - CERQUeIRA, N.L. Descriçāo da larva e pupa de Aedes (Ochierotatus) lepidus Cerqueira \& Paraense - (Diptera Culicidae, Culicini). Belém, 1957. 4 p., 2 est.

04 - CARVAlho, Cory T. de. A nidificação do Turdus I. albiventer Spix (Passeres: Turdidae). Belém, 1957. 13 p., il., 1 tab.

05 - CARVAlho, Cory T. de. Notas sobre a bio logia do Ramphocelus carbo (Passeres: Traupidae). Belém, 1957. 20 p., il., 1 tab.

06 - CARVAlHo, Cory T. de. Alguns mamiferos do Acre Ocidental. Belém, 1957. 22 p.

07 - CARVALHO, Cory T. de. Relaçōes biológicas entre Columbigalli napasserina e C. talpacoti (Aves, Columbidae). Belém, 1957. 15 p.

08 - NOVAES, FERNANDO C. Notas de Ornitologia Amazônica 1. Gêneros Formicarius e Phlegopsis. Belém, 1957. $9 \mathrm{p}$.

09 - NOVAES, Fernando C. Contribuição à Ornito. logia do noroeste do Acre. Belém, 1957. $30 \mathrm{p}$.

10 - CARVAlho, Cory T. de. Notas ecológicas sobre Coereba flaveola (Passeres, Coerebidae). Belém, 1958. 21 p., il., tab. 
11 - CUNHA, Osvaldo Rodrigues da. 1. Lacertílios da Amazônia. Sobre a ocorrência do gênero Bachia Gray. 1845, na Amazônia Brasileira. (Lacertilia-Teiidae). Belém, 1958. 12 p., 1 est.

12 - TRAVASSOS, Lauro. Gênero Schausiella Bouvier. 1930 (Lepidoptera, Adelocephalidae). Belém, 1958. 39 p., 16 est.

13 - TRAVASSOS, Haroldo \& PINTO, Sérgio Ypiranga. Estudos sobre a familia Cichlidae. II Actinopterygii-Perciformes. Belém, 1958, 23 p., 3 est., 1 tab.

14 - NOVAES, Fernando C. As Aves e as comunidades bióticas no alto Rio Juruá. Território do Acre. Belém, 1958. 13 p., il., tab.

15 - TRAVASSOS, Lauro \& KLOSS, G.R. Relatório da excursão do Instituto "Osvaldo Cruz" e Museu Nacional a Belém-Pará, de 2 a 17 de março de 1958. Belém, 1958. 10 p., mapa.

16 - SCHUBART, Otto. Sobre alguns Diplopoda do Estado do Pará (Brasil), colecionados por Lauro Travassos. Gertrud Rita Kloss e Fernando D.A. Pires. Belém, 1958. 30 p., 2 est.

17 - TRAVASSOS, Lauro \& KLOSS, G.R. Icthyocephalidae Família Nova (Nematoda). Belém, 1958. 19 p., 5 est.

18 - CARVAlHO, Cory T. de. Notas biológicas sobre Chlorestes notatus (Reich) (Aves, Trochilidae). Belém, 1958. 18 p., 1 est., il., tab.

19 - AVILA-PIRES, Fernando Dias de. Mamíferos colecionados nos arredores de Belém do Pará. Belém, 1958. 9 p., tab.

20 - CARVAlho, Cory T. de. Sobre o ninho e os ovos de Cyanerpes cyaneus (Linné) (Passeres, Coerebidae). Belém, 1958. $6 \mathrm{p}$.

21 - KLOSS, G.R. Nematódeos parasitando Hydrophilidae (Coleoptera) dos arredores de Belém (Estado do Pará, Brasil). Belém, 1959. 19 p., 5 est.

22 - NOVAES, Fernando C. Variação geográfica e o problema da espécie nas aves do grupo Ramphocelus carbo. Belém, 1959. 63 p., tab., diagrs.

23 - TRAVASSOS, Haroldo \& PINTO, Sérgio Ypiranga. Estudo sobre a familia Cichlidae III (Actinoptergii-Perciformes). Belém, 1959. 18 p., 4 est., 1 tab.

24 - SANTOS, Newton Dias dos \& MACHADO, Angelo Barbosa. Contribuição ao conhecimento do gênero Chalcopteryx Selys, $1853 \mathrm{com}$ a descrição de uma nova espécie (Polythoridae: Odonata). Belém, 1960. 16 p., 15 figs., 2 tab.

25 - CERQueIRA, N.L. Uma nova espécie de Haemagogus do Amazonas (Diptera-Culicidae). Belém, 1960. 5 p., 12 figs.
26 - CERQUeIRA, N.L. Sobre uma n. sp. de Janthi-nosoma da série Lutzi e a descriçăo do macho de Pserophora (J.) circumflava Cerqueira, 1943 (Diptera-Culicidae). Belém, 1960, 7 p., 12 figs

27 - MOURE, J.S. CMF. Os tipos das espécies neotropicais de Hylaeus da coleção Vachal do Museu de História Natural de Paris - (Hymenoptera-Apoidea). Belém, 1960104 p.

28 - MOURE, J.S. CMF \& HURD Jr., Paul D. On the systematic position of three Anthidiine bees described by Adolfo Ducke (HymenopteraApoidae). Belém, 1960. 13 p., il.

29 - FREITAS, J.F. Teixeira de \& MENDONÇA, J.F. Machado de. Novo nematódeo tricostrongilideo parasito de quiróptero. Belém, 1960. 4 p., 2 est., 1 tab.

30 - FREITAS, J.F. Teixeira de. Sobre um novo parasito de anfíbio: Maicuru solitarium g.n., $\mathrm{sp}$. n. (Trematoda-Plagiorchidae) Belém, 1960. 4 p., 1 fig.

31 - TRAVASSOS, Haroldo \& PINTO, Sérgio Ypiranga. Estudos sobre a família Cichlidae IV (Actinopeterygii-Perciformes). Belém, 1960. 13 p., 4 est.

32 - FREITAS, J.F. Teixeira de. Primeira espécie brasileira do gênero Brachycoelium Dujardin, 1845. Belém, 1961. 4 p., tab.

33 - BECHYNE, Jan \& BECHYNÉ, Bohumila Springlová de. Notas sobre Chrysomeloidea Neotropicais. Belém, 1961. 50 p., 7 est.

34 - SANTOS, Newton Dias dos. Inpabasis g.n. s três espécies novas (Coenagridae-Odonata). Belém, 1961. 7 p., 2 est.

35 - KLOSS, G.R. Parasitos intestinais do diplopoda Scaphiostreptus buffalus Schubart. Belém, 1961. 13 p., 4 est.

36 - SATTLER, Werner. Ein in den Metamorphosestadien aquatisches, polyrheobiontes lepidopter (Elophila, Pyralidae) aus dem Tumucumaque-Bergland (Brasilianisch Guayana) I. Belém, 1961. 9 p., est., map.

37 - BECHYNÉ, Jan \& BECHYNÉ, Bohumila Springlová de. Notas sobre Chrysomeloidea Neotropicais II. Belém, 1961. 93 p., il.

38 - SANTOS, Newton Dias dos. Acanthagrion egleri sp. n. (Coenagriidae-Odonataj. Belém, 1961. 4 p., 1 est.

39 - CUNHA, Osvaldo Rodrigues da. II Lacertílios da Amazônia - Os Lagartos da Amazônia Brasileira, principalmente dos representados na coleção do Museu Goeldi, Belém, 1961. $189 \mathrm{p}$. 
40 - NOVAES, Fernando C. Uma nova subespécie de Turdus ignobilis Sclater do Estado do Pará e sobre a ocorrência de Turdus amaurochalinus cabanis na região de Belém. Belém, 1963. $4 \mathrm{p}$.

41 - ALBUQUEQUE, Isolda R.S. Check-list dos Blattaria brasileiros. Belém, 1964. $37 \mathrm{p}$.

42 - PIRES, Fernando Dias de Avila. Mamíferos colecionados na região do Rio Negro (Amazonas, Brasil). Belém, 1964. 23 p.

43 - OITICICA-FILHO, José. Sobre o tipo de Sphinx pellenia Herrich-Schaeffer (1854). Belém, 1964. 15 p., 6 est.

44 - ALBUQUERQUE, Isolda R.S. Sobre três espécies novas de Blattaria do Brasil (Epilampridae-Blattelinae). Belém, 1964. 6 p., 3 est.

45 - ALBUQUERQUE, Isolda R.S. On a collection of cockroaches from Venezuela (Arthoptera, Blattoidea). Belém, 1964. 22 p., 4 est.

46 - ALHO, Cleber J.R. Contribuição ao estudo do gênero Klossinemella Costa, 1961 - com descrição de uma nova espécie (Nematoda). Belém, 1964. 6 p., 2 est.

47 - NOVAES, Fernando C. Uma nova raça geográfica de Piprites chloris (Temminck) do Estado do Pará (Pipridae Aves). Belém, 1964. $5 \mathrm{p}$.

48 - ALBUQUERQUE, Isolda R.S. Sobre o gênero Lophoblatta Hebard, 1929, com descrição de uma espécie nova (Epilampridae-Blattellinae). Belém, 1964. 8 p., 2 est.

49 - REBOUCAS, Regina. Nota preliminar sobre anéis de crescimento nas escamas de Cichla ocelairis no Pará (Prisces, Cichlidae). Belém, 1964. 6 p., 3 est.

50 - AlBUQUeRQUE, Isolda R.S. Novas ocorrências de Blattellinae no Peru com descrição de três espécies novas (Epilampridae). Belém, 1964. 7 p., 2 est.

51 - MACHADO, Angelo B.M. Duas novas epipleoneuras dos rios Paru de Oeste e Amapari (Odonata-Protoneuridae). Belém, 1964. 13 p., 1 est.

52 - ALHO, Cleber J.R. Dois novos hospedadores de Nematophila grande (Diesing. 1839) (Trematoda; Paramphistomoidea). Belém, 1964. 4 p., 1 est.

53 - BECHYNÉ, Jan \& BECHYNÉ, Bohumila S. Notes sur les Chrysomeloidae capturés par le Dr. W.A. Egler au Rio Jari (Brésil: Pará/Amapá) en 1961. Belém, 1965. 44 p., 4 est.

54 - NOVAES, Fernando C. Notas sobre algumas aves da serra Parima, Território de Roraima (Brasil). Belém, 1965. 10 p.
55 - OITICICA-FILHO, José. Uma espécie nova do Gênero Automeris (Lepidoptera, Hemileucidae). Belém, 1965. 6 p., 4 est.

56 - OITICICA-FILHO, José. Sobre alguns tipos do gênero Manduca (Protoparce dos autores) no British Museum (Natural History) (Lepidoptera, Sphingidae). Belém. 1965. 29 p., 15 est.

57 - ALBUQUERQUE, Isolda R.S. Novas ocorrências de Blattaria no Brasil e descrição de três espécies novas (Orth. Blattoidea). Belém, 1965. 11 p., 2 est.

58 - ALHO, Cleber J.R. Contribuição ao conhecimento da fauna helmintológica de quelônios do Estado do Pará, Brasil. Belém, 1965. 8 p., 2 est., 1 tab.

59 - ALHO, Cleber J.R. Sobre uma espécie nova do gênero Diaphanocephalus Diesing, 1851, parasita de lagarto da Amazônia (Dracaena Guianensis Daudin) (Nematoda, Strongyloidea). Belém, 1965. 5 p., 2 est.

60 - ARLÉ, Roger. Collemboles D'Amazonie, I. Poduromorphes nouveaux ou peu connus et notes biologiques sur Neotropeella carli (Denis). Belém, 1966. 19 p., 13 est.

61 - CUNHA, Osvaldo Rodrigues da. Sobre uma nova espécie de lagarto do Estado de Minas Gerais Placossoma cipoense sp. n. (Lacertilia, Leiidae). Belém, 1966. 9 p., 1 est.

62 - AlBUQUERQUE, Isolda Rocha e Silva. Sobre o gênero Dendroblatta Rehn, 1916, com descrição de uma espécie nova (Dictioptera: Blattaria). Belém, 1966. 7 p., 1 est.

63 - ALBUQUERQUE, Isolda Rocha e Silva. Duas espécies novas de Anaplecta Burmeister da Amazônia (Dictioptera: Blattaria). Belém, 1966. 5 p., 3 est.

64 - NOVAES, Fernando C. Sobre algumas aves pouco conhecidas na Amazônia Brasileira. Belém, 1967. 8 p.

65 - AlbuQUeRQUE, Isolda Rocha e Silva. Sobre quatro espécies novas de baratas da Amazônia (Dictioptera: Blattaria). Belem, 1967. 6 p., 3 est.

66 - CUNHA, Osvaldo Rodrigues da. Ofícios da Amazônia. I. A ocorrência de Bothrops bilineatus bilineatus (Wied) nas matas dos arredores de Belém, Pará (Ophidia, Crotalidae). Belém, 1967. 12 p.

67 - CUNHA, Osvaldo Rodrigues da. Um teratódimo deródimo em jibóia (Constrictor constrictor constrictor) (Linn., 1766). (Ophidia, Boidae). Belém, 1968. 17 p., 3 est

68 - ARLÉ, Roger. Collemboles d'Amazonic. II. Pseudostachia folsomi gen. n. sp. n., intéressante espécie euédaphique. Belém, 1968. 7 p., 4 est. 
69 - NOVAES, Fernando C. Análise ecológica de uma avifauna da região do rio Acará, Estado do Pará. Belém, 1969. 52 p., 5 fig.

70 - CUNHA, Osvaldo Rodrigues da \& NASCIMENTO, F.P. Ofídios da Amazônia II. Liophis miliaris (Linneu, 1758) na Amazônia Norte Oriental (Território Federal do Amapá) (Ophidia, Colubridae). Belém, 1970. $6 \mathrm{p}$.

71 - NOVAES, Fernando C. Distribuição ecológica e abundância das aves em um trecho da mata do baixo rio Guamá (Estado do Pará). Belém, 1970. 54 p., 12 fig., 5 tab.

72 - ARLE, Roger. Uma nova espécie de Onychiurus (Collembola-Onychiuridae) de ocorrência periódica em Belém (Pará). Belém, 1970. 11 p., 2 fig., 1 est.

73 - CUNHA, Osvaldo Rodrigues da. Uma nova subespécie de quelônios, Kinosternon scorpioides carajasensis da serra dos Carajás, Pará (Testudinata-Kinosternidae). Belém, 1970. 12 p., 2 est.

74 - CUNHA, Osvaldo Rodrigues da. Lacertílios da Amazônia. IV. Um novo gênero e espécie de lagarto do Território Federal do Amapá (Lacertilia-Teiidae). Belém, 1970, 8 p.

75 - ARLÉ, Roger. Collemboles d'Amazonie. III. Quelques Symphypléones du Bas-Amazonie et complément à la description de Deuterosminthurus aueti Arlé, 1961. Belém, 1971. 11 p., 7 est.

76 - ALBUQUERQUE, Isolda Rocha e Silva. Inventário dos Blattaria da Amazônia, com descrição de três espécies novas. Be!ém, 1972. 8 p., il.

77 - PICCININI, Rogério Serrão. Lista provisória dos quirópteros da coleção do Museu Paraense Emílio Goeldi (Chiroptera). Belém, 1974. 32 p.

78 - PIMENTEL, Therezinha. Contribuição ao conhecimento de Chrysopilus fascipennis Bromley, 1931 (Diptera: Rhagionidae). Belém, 1975. $5 \mathrm{p}$.

79 - ALBUQUERQUE, Isolda Rocha e Silva \& FRAGA, Carlos Roberto Costa. Estudo sobre o gênero Xestoblatta Hebard, 1916 (Blattariae). Descrição de três espécies novas da Amazônia. Belém, 1975. 14 p., il.

80 - CUNHA, Osvaldo Rodrigues da \& NASCIMENTO, Francisco Paiva do. Ofídios da Amazônia V. Bothrops lichenosus Roze, 1958, sinônimo de Bothrops castelnaudi Duméril, Bibron e Duméril, 1854, com nova descrição e comentários. Belém, 1975. 14 p., 2 tab.
81 - CUNHA, Osvaldo Rodrigues da. Sobre a ocorrência da tartaruga de couro Dermochelys coriacea (Linnaeus, 1758) na foz do rio Amazonas. (Chelonia, Dermochelyidae). Belém, 1975. 16 p., il.

82 - CUNHA, Osvaldo Rodrigues da \& NASCIMENTO, Francisco Paiva do. Ofídios da Amazônia VI - Liotyphlops ternetzii (Boulenger, 1896), ofídio raro e de hábitos subterrâneos, na região leste do Pará (Ophidia, Anomalepididae). Belém, 1975. 8 p., il.

83 - CUNHA, Osvaldo Rodrigues da \& NASCIMENTO, Francisco Paiva do. Ofídios da Amazônia VII - As serpentes peçonhentas do gênero Bothrops (Jararacas) e Lachesis (Surucucu), da região leste do Pará (Ophidia, Viperidae). Belém, 1975. 42 p., 2 est., 1 qd. $1 \mathrm{gr}$.

84 - CUNHA, Osvaldo Rodrigues da \& NASCIMENTO, Francisco Paiva do. Ofídios da Amazônia VIII - A ocorrência de Rhinobothryum lentiginosum (Scopoli, 1785) nas proximidades de Belém, Pará (Ophidia, Colubridae). Belém, 1976. 6 p., 1 est.

85 - CUNHA, Osvaldo Rodrigues da \& NASCIMENTO, Francisco Paiva do. Ofídios da Amazônia IX - O gênero Liophis Wagler, 1830, na região leste do Pará (Ophidia, Colubridae). Belém, 1976. 32 p., il., 1 mapa, 2 est., 4 tab. 4 tab.

86 - CUNHA, Osvaldo Rodirigues da. Lacertílios da Amazônia. VI - Uma nova espécie de lagarto (Colobosaura landii) da região leste do Pará (Lacertilia, Teiidae). Belém, 1977. 13 p., il.

87 - ARLÉ, Roger \& OLIVEIRA, Miriam Mendes de. O gênero Temeritas Delamare \& Massoud, 1963, na Amazônia (Collembola Symphypleona). Belém, 1977. 23 p., il.

88 - ROCHA E SILVA, Isolda \& AGUIAR, Gustavo Martins de. Blattariae da Amazônia. Família Blaberidae da localidade Sinop, Estado de Mato Grosso, Brasil (Dictyoptera). Belém, 1977. 30 p., il.

89 - ARLÉ, Roger \& GUIMARÃES, Anthony Érico. Novas espécies de Entomobrya Rondani, 1861, do Estado do Pará (Collembola, Entomobryomorpha). Belém, 1978. 18 p., il.

90 - NOVAES, Fernando C. Sobre algumas aves pouco conhecidas da Amazônia Brasileira, II. Belém, 1978. $15 \mathrm{p}$.

91 - LOPES, Sonia Maria Rodrigues. I. Sobre alguns Muscidae novos e pouco conhecidos (Diptera). Belém, 1978. 16 p., il. 
92 - TADEI, Valdir Antonio; VIZOTO, Luiz Dino \& SA. ZIMA, Ivan. Notas sobre Lionycteris e Lonchophylla nas coleções do Museu Paraense Emílio Goeldi (Mammalia, Chiroptera, Phyl. lostomidae). Belém, 1978. 14 p., il.

93 - ANDRADE, Gabriel Simões de. Uma nova espécie do gênero Sphongophorus Fairmaire 1846 (Homoptera: Membracidae). Belém, 1978. 6 p., il.

94 - OVERAL, W.L. Designação de Lectótipos de onze espécies de vespas sociais descritas por Adolpho Ducke, e notas sobre a coleção Ducke (Hymenoptera: Vespidae). Belém, 1978. 14 p.

95 - NASCIMENTO, Paulo T.R. \& OVERAL, W.L. Contribuiçōes entomológicas de Adolpho Ducke: Taxonomia e Bibliografia. Belém, 1979. $17 \mathrm{p}$.

96 - BANDEIRA, Adelmar Gomes. Notas sobre a fauna de cupins (Insecta: Isoptera) do Parque Nacional da Amazônia (Tapajós), Brasil. Abril, 1979. $12 \mathrm{p}$.

97 - NASCIMENTO, Paulo T.R. \& OVERAL, W.L. Ca. tálogo de tipos entomológicos da coleção do Museu Goeldi. Coleoptera: Chrisomelidae (Insecta). Belém, 1979. 29 p.

98 - NASCIMENTO, Paulo T.R. Catálogo de tipos entomológicos do Museu Goeldi. Hymenoptera. Belém, 1979. $18 \mathrm{p}$.

99 - NASCIMENTO, Paulo T.R. \& OVERAL, W.L. Catálogo da coleção entomológica do $\mathrm{Mu}$ seu Goeldi. Hymenoptera: Sphecidae. Belém, 1980. $14 \mathrm{p}$.

100 - NOVAES, Fernando C. Observaçōes sobre a avifauna do alto curso do rio Paru de Les. te, Estado do Pará. Belém, 1980. 58 p., il.

101 - JEANNE, Roberto L. Observaçōes sobre limpeza e reutilização de células em ninhos de vespas sociais (Hymenoptera: Vespidae). Belém, 1980. 8 p.

102 - CUNHA, Osvaldo Rodrigues da \& NASCIMENTO, Francisco Paiva do. Ofídios da Amazônia $\mathrm{XI}$ - Ofídios de Roraima e notas sobre Erythrolamprus bauperthuisii Duméril, Bibron \& Duméril, 1854. Sinônimo de Erythrolamprus aesculapii aesculapii (Linnaeus, 1758). Belém, 1980. 21 p.

103 - CUNHA, Osvaldo Rodrigues da; NASCIMENTO. Francisco Paiva do; HOGE, Alphonse Richard. Ofídios da Amazônia XII - Uma subespécie nova de Sibynomorphus mikani do Noroeste do Maranhão (Ophidia: Colubridae, Dipsadinae). Belém, 1980, $15 \mathrm{p}$.

104 - TEIXEIRA, Dante Martins \& BEST, Robin C. Adendas à Ornitologia do Território Federal do Amapá. Belém, 1981. 25 p., il.
105 - PY-DANIEL, L.H. Rapp. Furcodontichthys novaesi n. gen. n. sp. (Osteichthyes, Siluriformes; Loricariidae) na bacia amazônica, Brasil. Belém, 1981. 17 p., il.

106 - NOVAES, Fernando C. A estrutura da espécie nos periquitos do gênero Pionites Heine (Psittacidae, Aves). Belém, 1981. 21 p, il.

\section{PUBLICAÇÕES AVULSAS DO MUSEU PARAENSE EMILIO GOELDI}

01 - BRASIL NETO, Anibal. A bacia dos formadores do Xingu. Aspectos gerais. Belém, 1964, 8 p., il.

02 - TRAVASSOS, Lauro \& FREITAS, J.F. Teixeira de. Pesquisas helmintológicas realizadas em Maicuru, Estado do Pará. Belém, 1964. 17 p.

03 - DERBYSHIRE, Desmond. Textos Hixkaryâna. Belém, 1965. $206 \mathrm{p}$.

04 - CORREAA, Conceição de M.G. Estatuetas de cerâmica na cultura Santarém. Belém. 1965. 88 p. il.

05 - FRANCISCO, Benedicto H.R. et alii. Contribuição à goelogia da Folha de São Luiz (SA-23) no Estado do Pará. 1 - Sinopse preliminar. Belém, 1966. 12 p., il.

06 - SIMŌES, Mário F., ed. Programa Nacional de Pesquisas Arqueológicas. Resultados preliminares do primeiro ano: 1965-1966. Belém, 1967. 158 p. il.

07 - FRIKEL, Protásio. Os Xikrin. Equipamento e técnicas de subsistência. Belém, 1968. 119 p. il.

08 - SILVA, Anaiza. Alguns elementos para o estudo do negro na Amazônia. Belém, 1968. 23 p. il.

09 - FRANCISCO, B.H.R. \& LOEWENSTEIN, Pedro. Léxico estigráfico da região norte do Brasil. Belém, 1968. 93 p.

10 - SIMŌES, Mário F., ed. Programa Nacional de Pesquisas Arqueológicas. 2 - Resultados preliminares do segundo ano: 1966-67. Belém, 1969. $151 \mathrm{p}$. il.

11 - LOEWENSTEIN, Pedro, et alii. Bibliografia e Indice da Geologia da Amazônia Legal Brasileira, 1641-1964. Belém, 1969. 291 p.

12 - BROCHADO, José P. et alii. Arqueologia brasileira em 1968. Um relatćrio preliminar do Programa Nacional de Pesquisas Arqueológicas. Belém, 1969. 33 p., il.

13 - SIMÕES, Mário F., ed. Programa Nacional de Pesquisas Arqueológicas. $3-$ Resultados preliminares do terceiro ano: 1967-68. Belém, 1969. 172 p., il. 
14 - FRIKEL, Protásio. Os Kaxúyana; notas etno-históricas. Belém, 1970. 82 p., il.

15 - SIMÕ̃E, Mário F., ed. Programa Nacional de Pesquisas Arqueológicas. 4 - Resultados preliminares do quarto ano: 1968-1969. Belém, 1971. 174 p., il.

16 - FRIKEL, Protásio. Dez anos de aculturação Titiyó (1960-1970). Belém, 1971. 112 p., il.

17 - CAVAlcante, Paulo B. Frutas comestiveis da Amazônia I. Belém, 1972. 84 p., il.

18 - SIMOES, Mário F. Indice das fases arqueológicas brasileiras. Belém, 1972. 75 p., il.

19 - FRIKEL, Protásio \& CORTEZ, Roberto. Elementos demográficos do Alto Paru de Oeste, Tumucumaque brasileiro. Indios Ewahoyána, Kaxúyana e Tiriyó. Belém, 1972. 102 p., il.

20 - SIMŌES, Mário F., ed. O Museu Paraense Emílio Goeldi no ano do Sesquicentenário. Belém, 1973. 286 p., il.

21 - NOVAES, Fernando da C. Aves de uma vegetação secundária na foz do Amazonas. Belém, 1973. 88 p., il.

22 - ARNAUD, Expedito. Aspecto da legislaçăo sobre os índios do Brasil. Belém, 1973. 45 p.

23 - CUNHA, Osvaldo Rodrigues da \& BASTOS, Therezinha Xavier. A contribuição do Museu Paraense Emílio Goeldi à meteorologia da Amazônia. Belém, 1973. 42 p. 34 tab.

24 - CAVAlCANTE, Paulo B. \& FRIKEL, Protásio. A Farmacopéia Tiriyó. Estudo Étno-Botânico. Belém, 1973. $145 \mathrm{p}$.
25 - NOVAES, Fernando da C. Ornitologia do Amapá I. Belém, 1974. 121 p.

26 - SIMŌES, Mário F., ed. Programa Nacional de Pesquisas Arqueológicas. $5-$ Resultados preliminares do quinto ano: 1969-1970. Belém, 1974. il.

27 - CAVAlCANTE, Paulo B. Frutas comestiveis da Amazônia. II. Belém, 1974. 73 p., il.

28 - ARNAUD, Expedito C. Os índios Gaviōes de Oeste. Pacificação e Integraçăo. Belém, 1975. 86 p.

29 - NOVAES, Fernando C. Ornitologia do Território do Amapá II. Belém, 1978. 75 p.

30 - SIMŌES, Mário F. \& ARAÚJO-COSTA, Fernanda. Areas da Amazônia Legal Brasileira para pesquisa e cadastro de sítios arqueogicos. Belém, 1978. 160 p., il.

31 - CUNHA, Osvaldo Rodrigues da \& NASCIMENTO Francisco Paiva do. Ofídios da Amazônia: as cobras da Região Leste do Pará. Belém, 1978. 218 p., il.

32 - BRABO, Maria José C. Os roceiros de Muaná. Belém, 1979. 70 p., il.

33 - CAVAlCANTE, Paulo B. Frutas comestiveis da Amazônia III. Belém, 1979. 62 p., il.

34 - SILVEIRA, Isolda Maciel da. Quatipuru - Agricultores, pescadores e coletores em uma vila Amazônica. Belém, 1979. 82 p., il.

35 - BIBLIOGRAFIA e INDICE da Geologia da Amazônia Legal Brasileira, 1965-1975. Belém, 1980. $176 \mathrm{p}$. 